\title{
The Reduction of Chrome in UG-2 Flotation Concentrate by Hydrometallurgical Means
}

\author{
Abel Monele Mokadze ${ }^{1,2,3,{ }^{*}, \text { Sehliselo Ndlovu }}{ }^{1,2}$, Alan Shemi ${ }^{1,2}$, Marek Dworzanowski ${ }^{1}$ \\ ${ }^{1}$ School of Chemical and Metallurgical Engineering, University of the Witwatersrand, Johannesburg, South Africa \\ ${ }^{2}$ DSI/NRF SARChI: Hydrometallurgy and Sustainable Development; University of the Witwatersrand, Johannesburg, South Africa \\ ${ }^{3}$ Betachem (Pty) Ltd, Plot 5, Producta, Driemanskap, Gauteng, South Africa
}

Email address:

abelmokadze@gmail.com. (A. M. Mokadze), Sehliselo.Ndlovu@wits.ac.za (S. Ndlovu)

${ }^{*}$ Corresponding author

\section{To cite this article:}

Abel Monele Mokadze, Sehliselo Ndlovu, Alan Shemi, Marek Dworzanowski. The Reduction of Chrome in UG-2 Flotation Concentrate by Hydrometallurgical Means. International Journal of Mineral Processing and Extractive Metallurgy. Vol. 6, No. 3, 2021, pp. 41-52. doi: 10.11648/j.ijmpem.20210603.12

Received: July 7, 2021; Accepted: July 29, 2021; Published: August 4, 2021

\begin{abstract}
The South African platinum industry has advanced into an era of predominantly mining and processing Upper Group Two (UG-2) ore to extract Platinum Group Metals (PGMs). Flotation concentrates derived from processing UG-2 ore are typically characterized by high chrome contents ( $>3 \mathrm{wt} . \%)$ which are not amenable to conventional PGM smelters. The net effect of high chrome, inter alia, includes increased smelting energy requirements and the reduction of effective furnace capacity. Various interventions ranging from the redesign and modification of existing physical and pyrometallurgical operations have been introduced and these have yielded no sustainable solutions. In this study, a hydrometallurgical process was investigated as an alternative route to reduce chrome in UG-2 concentrates. The parameters initially considered for investigation were acid concentration, leaching time, temperature and oxygen flowrate while keeping solid to liquid ratio and agitation rate constant. Results showed that oxygen flowrate and an interaction of temperature, time and acid concentration had a positive but minimal effect on $\mathrm{Cr}$ extraction. The highest $\mathrm{Cr}$ extraction obtained was $7.0 \%$. Further test work entailed exploring the effect of solid to liquid ratio using optimized conditions. The results showed a substantial increase of $\mathrm{Cr}$ extraction of up to $37 \%$. This represents $1.33 \%$ decrease in chrome content, from $3.63 \%$ to $2.30 \%$, in UG-2 concentrate.
\end{abstract}

Keywords: PGM Smelting, UG-2 Concentrate, Chromite, Leaching

\section{Introduction}

The South African (SA) platinum industry has advanced into an era of predominantly mining and processing the Upper Group Two (UG-2) ore of the Bushveld Igneous Complex to extract Platinum Group metals (PGMs). This trajectory has been largely influenced by the depletion of accessible Merensky reserves and the limited availability of Platreef ore. The mineralogical and chemical compositions of the Merensky and Platreef flotation concentrates are similar and are amenable to conventional PGM smelting furnaces $[23,15]$. Their compositions are typical of high quantities of sulphidic minerals and lower chromite content. In contrast, UG-2 concentrates are typically characterised by lower sulphide and higher chromite content. The inherent high chrome grades (>3 wt.\%) have fundamentally rendered the smelting of UG-2 concentrates unattractive and difficult to process using the current PGM smelting methods [23, 18, 27, $11,2,15]$.

The primary PGM smelting processes in SA occur exclusively in electric furnaces; viz. rectangular six-in-line submerged-arc furnaces and circular three-electrode furnaces. In all smelters that use either of the two designs, the main objective of the unit operation is to form a molten bath comprised of immiscible dense sulphidic matte and light oxidic slag phases [15]. The common composition of the matte phase contains molten prills of base metals, iron and sulphur that act as PGM collectors, while the slag mainly contains silica and magnesia. The efficiency of PGM furnaces to achieve optimum matte-slag separation is mainly influenced by slag chemistry and furnace operating 
conditions. Slag chemistry is normally a function of feed composition, i.e., total iron oxide, silica, magnesia, and chrome. Typical smelting conditions of UG-2 material include slag liquidus temperatures of $1300-1500^{\circ} \mathrm{C}$ and oxygen potentials of $10^{-8}-10^{-9}$ bar $[22,7,2,20]$.

The solubility limit of chrome to deport in the silica glass phase is approximately 1.8 wt.\% and below [7]. Above this limit, the slag phase reaches saturation limits and results in chrome forming a partially liquid layer of refractory chrome spinel phases between slag and matte phases [22, 8, 7]. These phases are typically characterized by the following physical properties, which renders their formation undesirable:

1) High compound stabilities that are characterised by high melting point.

2) High viscosity and density.

3) Low solubility in silicic slags and partial solubility in matte.

4) High specific heat capacities of between 40 $\mathrm{Cal} / \mathrm{mole} /{ }^{\circ} \mathrm{C}$ and $55 \mathrm{Cal} / \mathrm{mole} /{ }^{\circ} \mathrm{C}$.

The technical problems that are commonly associated with the presence of the refractory chrome spinel phases in the conventional PGM smelting furnaces include:

1) A build-up of spinel phases on furnace sidewalls and hearth hence reducing effective furnace capacity.

2) Suspended spinel phases increase slag viscosity, thus causing poor slag-matte separation and entrapment of matte prills containing PGMs.

3) Increased slag thermal resistance which in turn increases slag liquidus temperature, refractory wear and power consumption.

It is evident, from the foregoing observations that the technical problems associated with processing high chrome feed, result in inefficiencies and high operating costs (OPEX) for the current traditional PGM smelters. Since the advent of processing enriched UG-2 material, SA platinum producers have adopted and developed various solutions to control and mitigate problems associated with high chrome feed. The solutions include the dilution of UG-2 concentrates, the use of gravity techniques and the modification of pyrometallurgical processes.

The dilution of UG-2 concentrates with the Merensky type of material has been widely used for decades to dilute chrome and other notorious oxides [15]. This has been considered as the most reliable processing strategy to modify the slag chemistry for efficient chromium solubility. The UG2: Merensky dilution ratios typically vary between 70:30 and 90:10. This practice is however fast becoming non-viable as the remaining resources of Merensky ore are at levels that are too deep for economic extraction. Spiral and hydrocyclone gravity techniques have also found large application in UG-2 mill-float-mill-float (MF-2) plant configurations to recover and prevent overgrinding of chromite prior to flotation [18, 21]. These technologies are generally inefficient to separate fine chromite and coarse silicates due to their major differences in specific densities, i.e., fine chromite phases of density 4.2 , are typically recovered with coarse silicates of density 2.7 .
The common pyrometallurgical solution that has found significant application in the smelting of enriched-chrome concentrates is furnace technology with high hearth power densities $[8,20]$. This technology can operate at high liquidus temperature that solubilizes chromium into slag glass $[8,7]$. This is typically accompanied by a hybrid design of furnace plate coolers and graphite waffle coolers on the lower and upper sidewalls of the furnace. Some smelters are using this with temperature monitoring systems in the form of fibreoptics to monitor the wear of liners and tapholes of the furnace [23, 8]. However, higher energy inputs and the regular maintenance required remain the major drawbacks of the technology. Other pyrometallurgical solutions that have not found industrial application include metallic alloy smelting that uses an iron-rich alloy as a PGM collector [13, $14,16]$, a selective solidification process that involves the tapping of spinel layer [2], and the modification of smelting conditions by adding reductants.

In this study, a hydrometallurgical option was investigated to reduce chrome in Sibanye-Stillwater's Eastern Platinum (EPL) UG-2 flotation concentrate to levels compatible with the stability of the slag glass phase. The circular threeelectrode furnaces used at Sibanye-Stillwater's smelter can efficiently process furnace feed containing approximately 1.8 wt.\% and below of chrome due to their high hearth power densities. EPL flotation concentrates typically contains 3-5 wt.\% chrome content depending on the efficiency of upstream unit operations. The material used in this investigation contained $3.6 \mathrm{wt}$ \% $\%$ chrome content.

Previous studies conducted on the leachability of chromium from chromite ores under acidic conditions, were used to form the scientific basis in this study [19, 32, 30, 12, $33,10,29,1]$. The major process factors and conditions that were employed in these studies involved acid concentration $(40-85 \% \mathrm{v} / \mathrm{v})$, temperature $\left(140-210^{\circ} \mathrm{C}\right)$, leaching time $(1-6$ hr.), solid to liquid ratio $(1: 10-1: 25)$, etc.; and chromium extractions of $70-85 \%$ were achieved. [32, 31, 33] investigated the effect of acid concentration, an oxidant and temperature, on the formation of chromium (III) sulphates. The authors found that the oxidant increased the rate of reaction, while acid concentration $(82 \% \mathrm{v} / \mathrm{v})$ and temperature $\left(140-210^{\circ} \mathrm{C}\right)$ favored the formation of thin boundary layers of metal sulphates comprising $\mathrm{Fe}_{2}\left(\mathrm{SO}_{4}\right)_{3}, \mathrm{MgSO}_{4}$ and $\mathrm{Cr}_{2}\left(\mathrm{SO}_{4}\right)_{3}$. Similar patterns in chromium dissolution and the formation of insoluble metal sulphates are consistent with findings by $[10,12,33]$ under similar process conditions explored by [29].

Under acidic-oxidative conditions, the chemical equilibrium of $\mathrm{Cr}$ in the $\mathrm{Cr}-\mathrm{O}-\mathrm{H}$ system is aqueous and stable under $\mathrm{pH}<3.5$ and $\mathrm{Eh}$ range of -0.4 and 1.5 volts as documented by [25] and displayed in Figure 1. In the current study, sulphuric acid was selected as the main lixiviant due to its strong oxidizing properties which allow for effective solubilization of metals, cost efficiency, environmental safety, and ease of use. Pure oxygen was used to re-in force an oxidative environment. 


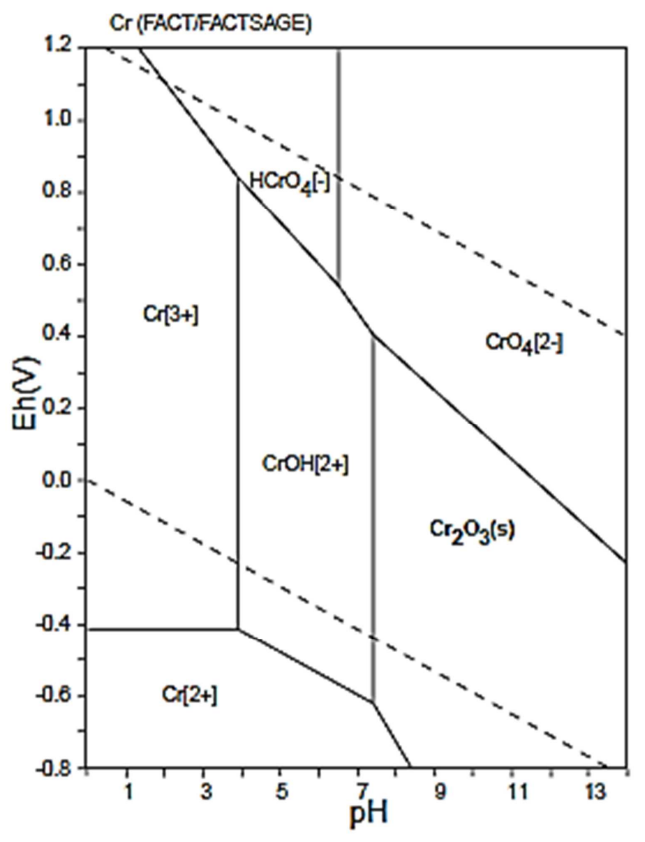

Figure 1. Eh-pH diagrams of the system Cr-O-H. 298.15K, 10 $\mathrm{Pa}$ [23].

The chromite dissolution mechanism mainly involves the reaction of the chromite crystal structure with an acid [29, 1, $3,5]$. The hydronium ion reacts with the chromite crystal structure causing the chromite to become oxidized thus inducing metal dissolution. The process chemistry entails the dissolution of the divalent metals in the tetrahedral site, followed by the dissolution of the trivalent metals in the octahedral site of chromite. Equation (1) shows the typical chemical dissolution of chromite under acidic-oxidative conditions:

$$
\begin{gathered}
\left(\mathrm{Mg}_{\mathrm{a}}, \mathrm{Fe}_{\mathrm{b}}\right)\left(\mathrm{Cr}_{\mathrm{c}}, \mathrm{Al}_{\mathrm{d}}, \mathrm{Fe}_{\mathrm{f}}\right)_{2} \mathrm{O}_{4}+8 \mathrm{H}^{+}-\mathrm{be}^{-}=\mathrm{aMg}^{2+}+(\mathrm{b}+2 \mathrm{f}) \mathrm{Fe}^{3+} \\
+2 \mathrm{cCr}^{3+}+2 \mathrm{dAl}^{3+}+4 \mathrm{H}_{2} \mathrm{O}
\end{gathered}
$$

Where $\mathrm{a}, \mathrm{b}, \mathrm{c}, \mathrm{d}$ and $\mathrm{f}$ are coefficients; $\mathrm{a}+\mathrm{b}=1$ and $\mathrm{c}+\mathrm{d}+$ $\mathrm{f}=1$.

This process brings the metallic contents of chromite into the bulk solution in similar proportions to their formation in the crystal structure [3]. In the presence of an oxidant, the degree of dissolution significantly improves as the oxidation rate of divalent metals in the tetrahedra site increase [19, 30, $12,29,27]$. In the sulphate system ( $\mathrm{pH} \mathrm{0-3.5,} \mathrm{Eh} \mathrm{-04-1.5),}$ base metals and small fractions of individual precious metals solubilize into sulphate salts which go into solution where they could be selectively precipitated en route to the base metal processing unit. The co-dissolution of these metals is well known and documented in literature [17].

Chromite removal or minimization using hydrometallurgical intervention would have advantages of technical applicability, operational simplicity, and economic feasibility. The key benefits associated with the leach unit operation prior to smelting would be improved energy efficiencies in terms of furnace specific energy consumptions (SEC) $(\mathrm{kWh} / \mathrm{t})$, high PGM recoveries due to low slag viscosity, increased refractory life-span and high furnace utilization due to improved furnace availability.

Thus, this study is aimed at reducing chrome in PGM smelting furnace feed from 3.6 wt. $\%$ to levels below 1.8 wt.\%, using less energy intensive leaching conditions. The primary objectives of this study, therefore, include identifying factors that significantly influence the chromium dissolution process, optimizing leaching conditions and evaluating the effect of solid to liquid ratio under optimum leaching conditions. Process factors explored included acid concentration $(\% \mathrm{v} / \mathrm{v})$, leaching time (hour), leaching temperature $\left({ }^{\circ} \mathrm{C}\right)$ and oxygen flowrate $(\mathrm{mL} / \mathrm{min})$.

\section{Materials and Methods}

\subsection{UG-2 Flotation Concentrate}

The final UG-2 flotation concentrate used in the current study was supplied by Eastern Platinum concentrator, Sibanye-Stillwater (Pty) Ltd (formerly, Lonmin (Pty) Ltd), South Africa.

The mineralogical characterization of this sample was carried out at Betachem's process mineralogy laboratory using automated quantitative scanning electron microscopy (A-SEM). The mineralogical composition as well as the elemental deportment data are shown in Table 1. The A-SEM analysis entailed scanning a prepared polished stub using an ASPEX scanning electron microscope. This was equipped with Bruker energy dispersive X-ray spectrometer (EDS) which is operated by the Mineral Liberation Analysis (MLA) software suite. X-ray backscattered Electron Images (XBSE) measurement techniques were used to scan a minimum of 20 000 particles, or a maximum of 6 hours scan time for the sample. The mineral phases in the particles were identified using a best fit technique which uses MinIdent-Win4 software and the FEI-MLA mineral reference editor. The particle size distribution was determined by A-SEM and physical screening analysis using Tyler sieves screens ranging between +150 and -25 microns $(\mu \mathrm{m})$. The particle size distribution of this UG-2 concentrate sample is shown in Figure 1.

\begin{tabular}{|c|c|c|c|c|c|c|c|c|}
\hline \multicolumn{4}{|c|}{ Calc. Assay (wt.\%) } & \multirow{2}{*}{$\begin{array}{l}\text { Mass } \\
\text { Total }\end{array}$} & \multicolumn{4}{|c|}{ Elemental deportment } \\
\hline $\mathrm{Cr}$ & $\mathbf{F e}$ & Mg & Al & & $\mathrm{Cr}$ & $\mathrm{Fe}$ & Mg & Al \\
\hline 2 & 11,7 & 14,4 & 2,5 & Wt $\%$ & $\%$ & $\%$ & $\%$ & $\%$ \\
\hline \multicolumn{4}{|c|}{ Base metal sulphides } & 5,7 & 0 & 18 & 0 & 0 \\
\hline \multicolumn{4}{|c|}{ Talc-Enstatite } & 63,6 & 0 & 47 & 85 & 0 \\
\hline \multicolumn{4}{|c|}{ Plagioclase } & 5,4 & 0 & 0 & 0 & 37 \\
\hline \multicolumn{4}{|c|}{ K-Feldspar } & 0,1 & 0 & 0 & 0 & 0 \\
\hline \multicolumn{4}{|c|}{ Pyroxene } & 7.0 & 0 & 2 & 5 & 5 \\
\hline \multicolumn{4}{|c|}{ Quartz } & 2.0 & 0 & 0 & 0 & 0 \\
\hline \multicolumn{4}{|c|}{ Serpentine } & 0,9 & 0 & 1 & 2 & 0 \\
\hline \multicolumn{4}{|c|}{ Chromite } & 6,2 & 100 & 19 & 2 & 20 \\
\hline \multicolumn{4}{|c|}{ Mica } & 7,4 & 0 & 6 & 5 & 37 \\
\hline \multicolumn{4}{|c|}{ Carbonates } & 0,2 & 0 & 0 & 0 & 0 \\
\hline \multicolumn{4}{|c|}{ Oxides } & 1,3 & 0 & 7 & 0 & 0 \\
\hline \multicolumn{4}{|c|}{ Others } & 0,2 & 0 & 0 & 0 & 0 \\
\hline \multicolumn{4}{|c|}{ Total } & 100 & 100 & 100 & 100 & 100 \\
\hline
\end{tabular}

Table 1. Bulk mineralogy and elemental distribution of UG-2 concentrate. 


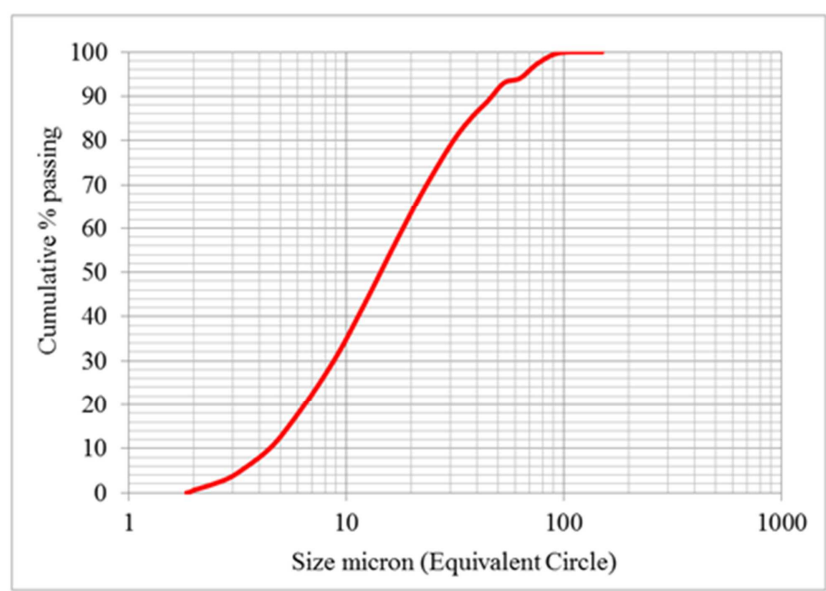

Figure 1. Particle size distribution of EPL UG-2 flotation concentrate.

The chemical composition of this sample determined using X-ray fluorescence (XRF) spectroscopy, is shown in Table 2. The analysis was conducted on the $-38 \mu \mathrm{m}$ size fraction as it constitutes the bulk of the sample material ( $85 \mathrm{wt} . \%$ ) and contains high chrome content (3.6 wt.\%). This size fraction contains 92 wt.\% of total chrome in the concentrate. ARL ADVANT'X SERIES was used as the instrumental model. The method of identification involved UIS-XF-PTA-T003.

Table 2. Chemical composition of EPL final concentrate (wt.\%).

\begin{tabular}{lllllllll}
\hline $\mathrm{Fe}_{2} \mathrm{O}_{3}$ & $\mathrm{SiO}_{2}$ & $\mathrm{MgO}$ & $\mathrm{Cr}_{2} \mathrm{O}_{3}$ & $\mathrm{CaO}$ & $\mathrm{Al}_{2} \mathrm{O}_{3}$ & $\mathrm{TiO}_{2}$ & $\mathrm{Na}_{2} \mathrm{O}$ & $\mathrm{Mn}_{3} \mathrm{O}_{4}$ \\
\hline
\end{tabular}

\begin{tabular}{llllllllll}
\hline 13,89 & 47,13 & 23,60 & 3,63 & 2,19 & 4,74 & 0,27 & 0,13 & 0,17 \\
\hline
\end{tabular}

\subsection{Reagents}

All reagents used in this study were of analytical grade and were purchased from Merck-Sigma Aldrich and Afrox (Pty) Ltd, South Africa. Sulphuric acid $(98 \%$ w/w), deionised water and pure oxygen were used in the experiments.

\subsection{Experimental Design}

\subsubsection{Factorial Design}

Statistical Design of Experiments (DOE) was used to investigate the leaching behaviour of chromium using a $2^{4}$ full factorial design. The selection of process factors and their levels were based on data from preliminary experiments and literature. The leaching factors were classified as varied and fixed variables. Varied factors included leaching time, temperature, acid concentration and oxygen flowrate, while solid to liquid ratio and agitation rate were fixed factors. The process factors and their levels are illustrated in Table 3.

Table 3. Process factors and factor levels.

\begin{tabular}{llll}
\hline Process factors & Low (-1) & Centre point (0) & High (+1) \\
\hline Time (hr) & 2 & 3 & 4 \\
Acid concentration (\%) & 45 & 60 & 75 \\
Temperature $\left({ }^{\circ} \mathrm{C}\right)$ & 43 & 62 & 80 \\
Oxygen Flow Rate (ML/min) & 10 & 20 & 30 \\
Solid to liquid ratio & & $1: 3$ & \\
Agitation Rate (rpm) & & 1000 & \\
\hline
\end{tabular}

\subsubsection{Data Analysis}

The method employed for experimental data analysis was the normal probability plots and the Pareto chart. The analysis allowed the assessment of non-replicated factorials and higher order interactions.

i. Normal probability plot of effects

The normal probability plot is a statistical method that is used to evaluate the significance of factors. In the assessment of effects from unreplicated factorials, occasionally real and meaningful higher-order interactions occur and therefore it is necessary to allow for selection [4]. However, [6]'s method by which effects are plotted on a normal probability plot often provides an effective way of helping with selection. This is the plot of the actual value of the effect estimates against their cumulative normal probabilities. If the effects had occurred simply as the result of random variation about a fixed mean, and the changes in levels of the independent variables had had no real effect at all on the response, then all the main effects and interactions would be distributed about zero (normal distribution). They would therefore plot on a normal probability plot as a straight line whereas significant effects will have a non-zero means and will not lie along the straight line. To see whether they do, the main effects are ordered in increasing order and plotted with an appropriate scale. The scale is obtained by employing the generalized equation [4]:

$$
P=(i-0.5) * \frac{100}{m}
$$

Where, $\mathrm{m}=$ total number of effects, $\mathrm{P}=$ Probability points, $\mathrm{i}=$ Order number 0

\section{ii. Pareto chart}

Plotting the effects on a Pareto chart provides an alternative and equally effective way of helping with the selection of significant factors. The Pareto chart is based on an algorithm that produces a statistically based acceptance limit of significance [24, 28]. The level of significance is represented by horizontal bar graphs. The statistical technique, based on the Pareto principle of the "vital few", is used for the selection of factors that produce a statistically significant overall effect. The critical value line that cuts across the bar graphs serves to separate the vital from the non-vital effects. The insignificant (non-vital) effects lie to the left side of the critical value line while those deemed significant (vital) lie beyond the line to the right side.

\subsubsection{Central Composite Rotatable Design}

The data for fitting the second order response was collected by using the central composite rotatable design (CCRD). The experimental results were analysed statistically by using the analysis of variance (ANOVA) using Fisher's ratio test; standard errors of model coefficient (t-test) and the coefficient of determination $\left(\mathrm{R}^{2}\right)$. For the variables under consideration, a second order polynomial regression model was proposed as follows: 


$$
y=\beta_{o}+\sum_{i=1}^{2} \beta_{i} x_{i}+\sum_{i=1}^{2} \beta_{i i} x_{i}^{2}+\sum_{i=1}^{2} \sum_{j=i+1}^{2} \beta_{i j} x_{i} x_{j}+\varepsilon
$$

\section{Where,}

$\hat{y}$ is the predicted response, $\beta_{\mathrm{o}}$ is the coefficient for intercept, $\beta_{\mathrm{i}}$ is the coefficient of linear effect, $\beta_{\mathrm{ii}}$ is the coefficient of quadratic effect, $\beta_{\mathrm{ij}}$ is the coefficient of interaction effect, $\varepsilon$ is a term that represents other sources of variability not accounted for by the response function; $\mathrm{x}_{\mathrm{i}}$ and $\mathrm{x}_{\mathrm{j}}$ are coded predictor variables for the independent factors. The coefficients of the regression model were estimated by fitting the experimental results using Design Expert ${ }^{1} 11$ software.

\subsubsection{Response Surface Methodology}

Response Surface Methodology (RSM) was used in this study. The main objective of employing RSM was to optimize the response surface that is significantly influenced by various process variables [26]. The RSM based on quadratic programming was used in conjunction with the central composite design (CCRD) for fitting of the experimental data and development of the model.

\subsubsection{Experimental}

The key components of the experimental apparatus included a $2000 \mathrm{~mL}$ leaching vessel, an agitator and a thermal reciprocal bath for the leaching process. A $1500 \mathrm{ml}$ Erlenmeyer flask, filter funnel and vacuum pump formed the filtration setup.

The leaching experiments entailed adding a $200 \mathrm{~g}$ of UG-2 concentrate to a $600 \mathrm{~mL}$ sulphuric acid solution with a set temperature as per test condition. The solid to liquid ratio (1:3) used in the current study was based on typical industry practice. The agitation mechanism was fixed and operated at $1000 \mathrm{rpm}$. The completion of each batch leaching test was followed by a filtration step to physically separate the green in colour primary leach liquor from the residue. The residue was subsequently washed off using deionized water to recover any entrapped leach liquor. The washing process was continuously conducted until the filtrate colour from the residue was colourless. Quantitatively, a colourless filtrate for experiments conducted with $45 \% \quad(\mathrm{v} / \mathrm{v}) \quad \mathrm{H}_{2} \mathrm{SO}_{4}$ concentration was attained with an average of $1400 \mathrm{~mL}$ wash water; while experiments conducted with $85 \%$ (v/v) $\mathrm{H}_{2} \mathrm{SO}_{4}$ concentration required an average of $2500 \mathrm{~mL}$ wash water. The primary leach liquor and washed liquor were then mixed to make a total leach liquor. The last step involved sampling the total leach liquor to obtain a representative sample for Atomic Absorption Spectroscopy (AAS) analysis.

\section{Results and Discussion}

\subsection{Significant Factors}

Chromium extraction results from experimental runs for the $2^{4}$ full factorial design with codified and actual values are given in Table 4.

The chromium extraction in the sulphuric acid leaching of
UG-2 concentrate presented in Table 4 was calculated as a percentage of chromium in leach liquor to that in the unprocessed UG-2 concentrate sample. The experimental data given in Table 4 was used to estimate the main and interaction effects according to the procedure described in section 2.3.2. The estimated main and interaction effects are presented in Figure 3 and Figure 4.

Examination of the individual factors on the normal probability plot in Figure 3 showed that oxygen flowrate (D) and acid concentration (C) were statistically significant. The significance of these main factors on the normal plot is seen in their distant distribution from the zero mean. The figure also shows the interaction of temperature, leaching time and acid concentration (ABC) to be statistically significant because of its distant distribution from the mean zero. The results in the Pareto chart shown in Figure 4 corroborated the findings illustrated by the normal probability plot of effects in Figure 3. The significance or non-insignificance of an effect on the Pareto chart is distinguished by the criticalvalue line below which the effect is deemed insignificant. Examination of the Pareto chart shows that effect D (oxygen flowrate), $\mathrm{C}$ (acid concentration) and $\mathrm{ABC}$ (interaction of variable temperature, time and acid concentration), are statistically significant factors.

A polynomial model of first order degree was derived to indicate the dependence of the response (chromium extraction) on the significant factors. A simplified expression of the regression model is presented as:

$$
\hat{\mathrm{Y}}=5.98-0.79 \mathrm{X}_{\mathrm{C}}+0.99 \mathrm{X}_{\mathrm{D}}+0.74 \mathrm{X}_{\mathrm{ABC}}
$$

Where, $\hat{\mathrm{Y}}$ is chromium extraction; $\mathrm{XC}, \mathrm{XD}$ and $\mathrm{XABC}$ are predictor variables which take on the value of -1 or +1 (low or high). The positive and negative signs in the model indicate that in order to maximize chromium extraction, these factors must be kept at low and high levels respectively.

\begin{tabular}{|c|c|c|c|c|c|}
\hline STD & $\begin{array}{l}\text { Temp } \\
\left({ }^{\circ} \mathrm{C}\right) \\
\end{array}$ & $\begin{array}{l}\text { Time } \\
\text { (hrs.) } \\
\end{array}$ & $\begin{array}{l}\mathrm{H}_{2} \mathrm{SO}_{4} \text { Conc } \\
(\%) \\
\end{array}$ & $\begin{array}{l}\mathrm{O}_{2} \text { Flowrate } \\
\left(\mathrm{mL} \cdot \mathrm{min}^{-1}\right)\end{array}$ & $\begin{array}{l}\mathrm{Cr} \\
\text { Extraction }\end{array}$ \\
\hline run & $\mathbf{A}$ & B & $\mathrm{C}$ & D & $(\%)$ \\
\hline 1 & - & - & - & - & 5,2 \\
\hline 2 & + & - & - & - & 7,9 \\
\hline 3 & - & + & - & - & 7,9 \\
\hline 4 & + & + & - & - & 2,9 \\
\hline 5 & - & - & + & - & 3,4 \\
\hline 6 & + & - & + & - & 4,2 \\
\hline 7 & - & + & + & - & 3,6 \\
\hline 8 & + & + & + & - & 4,8 \\
\hline 9 & - & - & - & + & 6,4 \\
\hline 10 & + & - & - & + & 8,2 \\
\hline 11 & - & + & - & + & 8,2 \\
\hline 12 & + & + & - & + & 7,4 \\
\hline 13 & - & - & + & + & 7,0 \\
\hline 14 & + & - & + & + & 5,2 \\
\hline 15 & - & + & + & + & 7,0 \\
\hline 16 & + & + & + & + & 6,3 \\
\hline
\end{tabular}

Table 4. Cr extraction results for the $2^{4}$ full factorial design.

*The actual factors levels coded as values of $(-1)$ and $(+1)$ in the table are as follows: A (Temperature): $43^{\circ} \mathrm{C}(-1)$ and $80^{\circ} \mathrm{C}(+1)$; B (Leaching time): $2 \mathrm{hrs}$ $(-1)$ and $4 \mathrm{hrs}(+1)$; $\mathrm{C}$ (Acid conc): 45\% (-1) and 75\% (+1); D (Oxygen flowrate): $10 \mathrm{~mL} / \mathrm{min}(-1)$ and $30 \mathrm{~mL} / \mathrm{min}(+1)$. 


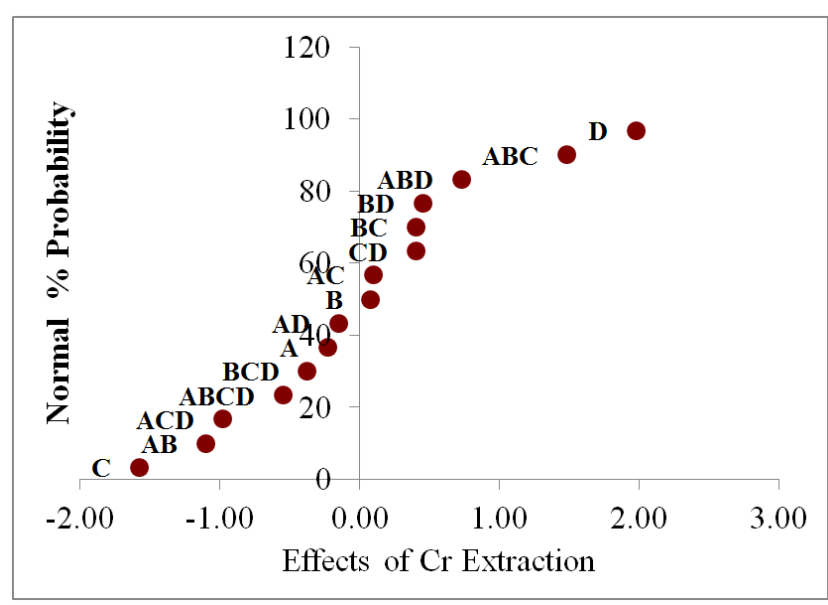

Figure 3. Normal probability plot of $2^{4}$ full factorial design of main and interacting factors. $A, B, C$ and $D$ are main factors: $A$ - temperature, $B$ time, $C$ - acid concentration, $D$ - oxygen flowrate. $A B, A C D, A B C D, B C D$, $A D, A C, B C, C D, B D, A B D$ and $A B C$ are interacting factors.

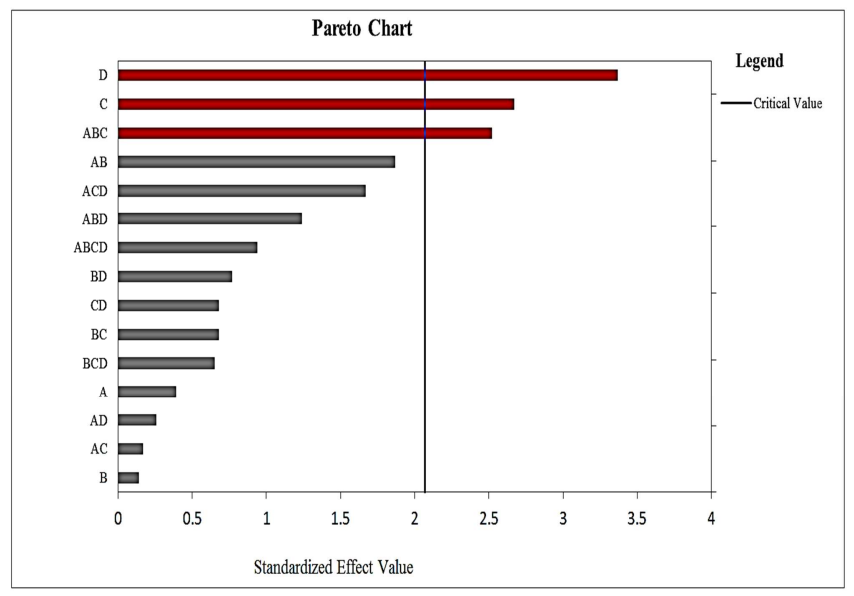

Figure 4. Pareto chart of $2^{4}$ full factorial design of main and interacting factors. $A, B, C$ and $D$ are main factors: $A$ - temperature, $B$ - time, $C$ - acid concentration, $D$ - oxygen flowrate. $A B, A C D, A B C D, B C D, A D, A C, B C$, $C D$.

\subsection{Influence of Process Factors on Chromium Extraction}

The interpretation of the influence of factors on the process response may be done in one of two ways: When factor interaction is absent, the variables can be interpreted individually. However, when factor interaction is evident, the variables must be interpreted jointly [4]. In this study, both cases applied. Therefore, all the factors were first interpreted individually and then the interaction factor $\mathrm{ABC}$ (leaching temperature, A; leaching time, B; acid concentration, C) variables were interpreted jointly.

\subsubsection{Effect of Temperature}

The effect of temperature on $\mathrm{Cr}$ extraction is shown in Figure 5. As shown in the figure, higher temperatures had a strong effect on $\mathrm{Cr}$ dissolution.

From $25^{\circ} \mathrm{C}$ to $43^{\circ} \mathrm{C}$, the dissolution of $\mathrm{Cr}$ increased sharply from $2.7 \%$ to $6.1 \%$. Between $43^{\circ} \mathrm{C}$ and $80^{\circ} \mathrm{C}$ the $\mathrm{Cr}$ extraction remained almost constant but increased steadily from $5.9 \%$ to $7.4 \%$ upon further increase in temperature to $98^{\circ} \mathrm{C}$. It can be deduced that at temperatures of $43-80^{\circ} \mathrm{C}$, the thermal energy required to enhance the collision frequency of molecules was insufficient for increasing the rate of reaction and further chromium dissolution [9]. Above this range, significantly higher $\mathrm{Cr}$ extraction has been demonstrated in research work done by authors such as [12, 29, 33]. These authors achieved definitive patterns in $\mathrm{Cr}$ extraction at temperatures of $140-210^{\circ} \mathrm{C}$ at a solid to liquid ratio of $1: 25$. The experiments in the current study were conducted at a fixed solid to liquid ratio of $1: 3$ and the highest leaching temperature of $80^{\circ} \mathrm{C}$.

In comparing the previous and current studies, the difference in leaching temperature between $140^{\circ} \mathrm{C}$ and $80^{\circ} \mathrm{C}$, and as well as the difference in solution volume based on 1:25 and 1:3 solid to liquid ratio, are noticeable. Therefore, the expected energy savings, based on the huge temperature difference and the large change in heated volume, are determined to be significant. In this study, the leaching temperature of $80^{\circ} \mathrm{C}$ was chosen as the appropriate level due to the cost implications of operating at high energy intensive leaching temperatures.

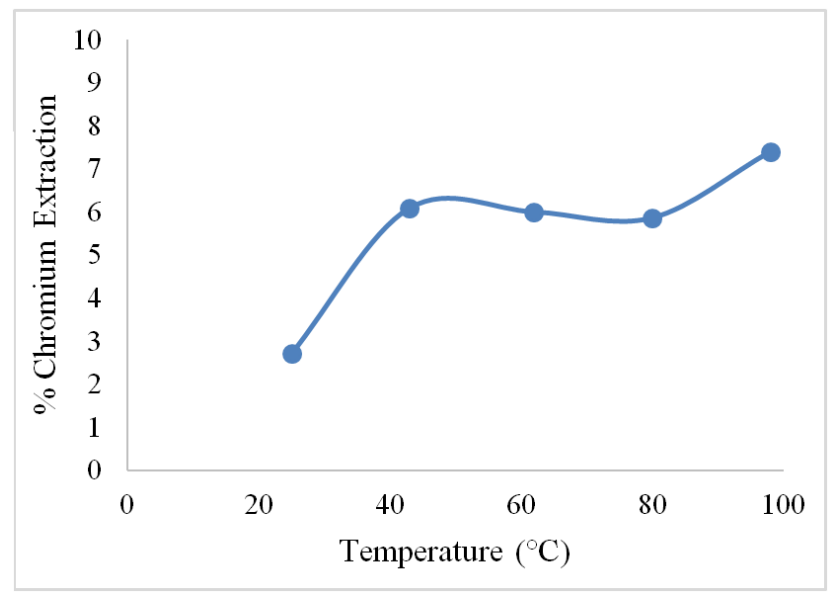

Figure 5. Cr extraction as a function of leaching temperature.

\subsubsection{Effect of Leaching Time}

The effect of leaching time is exhibited in Figure 6. A Cr extraction of $5.5 \%$ was obtained after $1 \mathrm{hr}$, and $6.0 \%$ after 6 hrs. The data shows a relatively high $\mathrm{Cr}$ extraction rate in the first $1 \mathrm{hr}$ and a much lower rate thereafter. The graph shows that $\mathrm{Cr}$ dissolution kinetics are very fast within the first $1 \mathrm{hr}$, which indicate that it is possible to achieve most of the $\mathrm{Cr}$ extraction within a shorter leaching time. The results further show that $\mathrm{Cr}$ extraction remained constant despite longer leaching times. This trend could be attributed to the formation of a boundary layer comprised of precipitated metal sulphates which passivate chromite mineral surfaces as observed in similar studies done by [12, 29, 33]. The other major contributing factor could be that, operating at high pulp densities could have increased the pulp viscosity, which in turn effectively caused poor diffusion. 


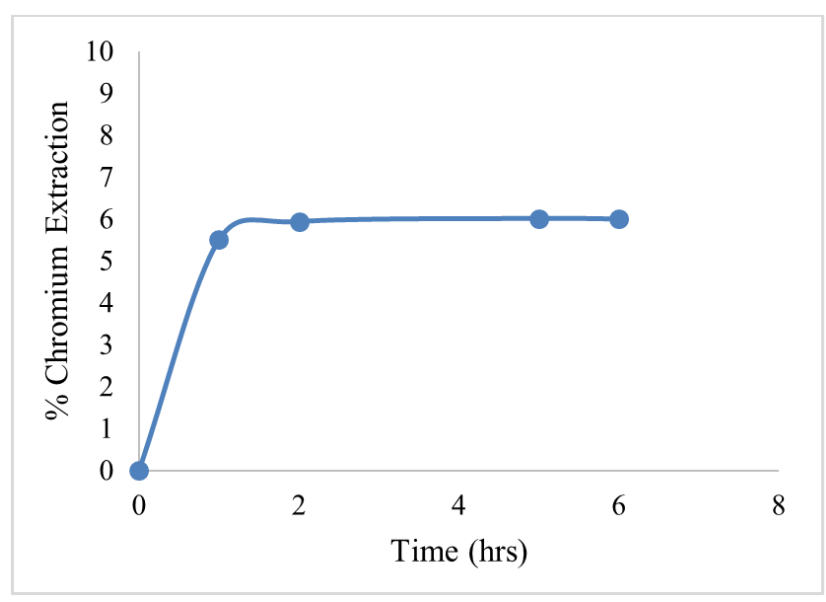

Figure 6. Cr extraction as a function of leaching time.

\subsubsection{Effect of Acid Concentration}

The effect of acid concentration on $\mathrm{Cr}$ extraction is illustrated in Figure 7. The results in the figure show that $\mathrm{Cr}$ dissolution increased with increasing acid concentration up to a maximum $\mathrm{Cr}$ extraction of $6.8 \%$ at $45 \%(\mathrm{v} / \mathrm{v})$ acid concentration. Further increase in acid concentration resulted in a decrease in $\mathrm{Cr}$ extraction. The negative effect of sulphuric acid on $\mathrm{Cr}$ extraction at higher acid concentrations is mainly attributed to the precipitation of metal sulphates that form boundary layers on chromite surfaces. The precipitates typically include $\mathrm{Fe}_{2}\left(\mathrm{SO}_{4}\right)_{3}, \mathrm{MgSO}_{4}$ and $\mathrm{Cr}_{2}\left(\mathrm{SO}_{4}\right)_{3}$ as observed in other similar studies. This boundary layer is known to form passivation species that limit the diffusion of products and reactants on chromite surfaces [12, $33,29]$. Therefore, $45 \%(\mathrm{v} / \mathrm{v})$ acid concentration was adopted as the peak and appropriate level and all subsequent experiments were performed at this level.

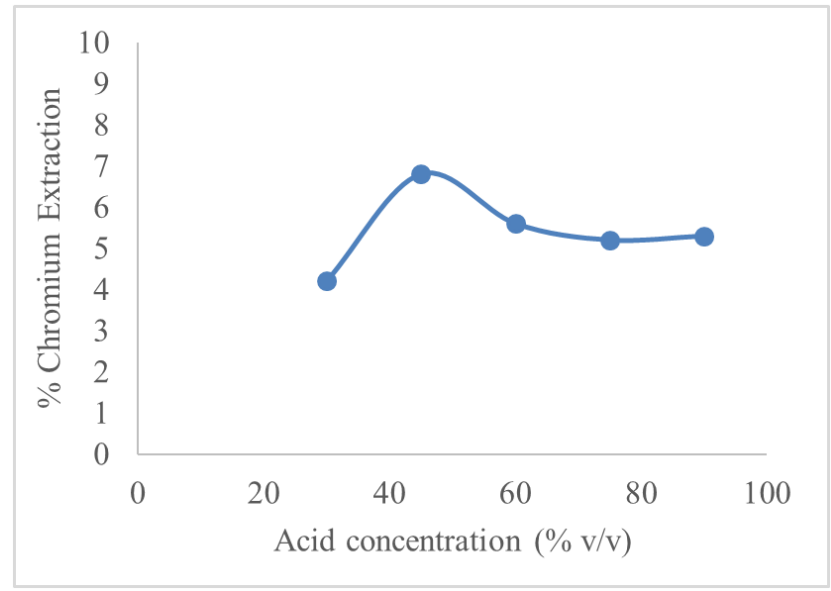

Figure 7. Cr extraction as a function of acid concentration.

\subsubsection{Effect of Oxygen Flowrate}

The effect of oxygen flowrate is shown in Figure 8. Oxygen was employed as an oxidant on the extraction of chromium from the UG-2 concentrate based on Figure 1. Figure 8 illustrates chromium extraction visa-vis oxygen flowrates at 0 and $40 \mathrm{~mL} / \mathrm{min}$. The extraction of $\mathrm{Cr}$ proportionally increased with the increase in oxygen flowrate up to a maximum of $6.2 \% \mathrm{Cr}$ extraction at $30 \mathrm{~mL} / \mathrm{min}$. Above $30 \mathrm{~mL} / \mathrm{min}$, oxygen flowrate did not promote a further dissolution in $\mathrm{Cr}$. Chromite was prone to dissolution due to the oxidation of iron (II) to iron (III) and chromium (III) to chromium (VI) in the tetrahedral and octahedral sites, respectively as observed by other research workers in previous studies $[31,12,33,10,29]$. In this experimental work, electro-potential (Eh) was measurement between 0.2 and 1.18 Volts. This Eh range was produced and maintained by the addition of oxygen as an oxidant, i.e., oxygen flowrates of $10-40 \mathrm{~mL} / \mathrm{min}$. This Eh range was measured under acid concentrations of between $5.8 \mathrm{M}(43 \% \mathrm{v} / \mathrm{v})$ and $11.6 \mathrm{M}(85 \% \mathrm{v} / \mathrm{v})$. Under these electrochemical conditions, the redox reactions in the tetrahedra and octahedra sites reduced the ionic radius of the constituent metals which in turn resulted in the instability of the chromite crystal structure; thus, inducing $\mathrm{Cr}$ dissolution [12, 33, 10, 29].

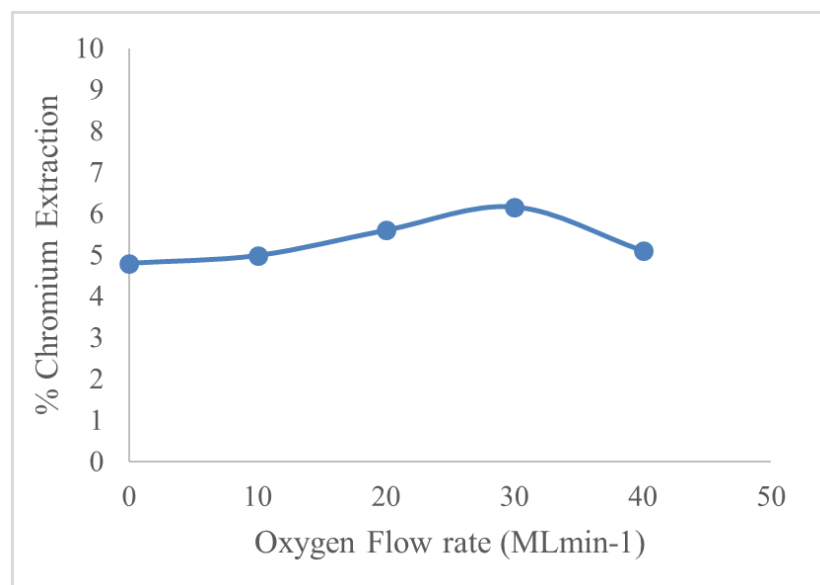

Figure 8. Cr dissolution as a function of oxygen flowrate.

\subsubsection{Effect of Interacting Factors}

The factor interaction effects were distributed around zero mean and fell along a straight line on the Normal plot (Figure 3). On the Pareto chart, all the interacting factors fell below the $\mathrm{t}$-value line except for the $\mathrm{ABC}$ factor interaction (Figure 4). Some outstanding interacting factors are shown in Figure 9. Among the factor interactions shown, the interaction of variables $\mathrm{AB}, \mathrm{AC}$ and $\mathrm{BC}$ were found to be statistically insignificant. The interaction of variables $\mathrm{ABC}$ (temperature, leaching time and acid concentration) was found to be statistically significant. When interpreted jointly, in the ranges studied, the $\mathrm{ABC}$ interaction was observed to have a positive influence on the $\mathrm{Cr}$ dissolution process. Analysis of the three variables $(\mathrm{ABC})$, displayed in Figures 5, 6 and 7, showed that the negative effect of higher acid concentration was counteracted by the joint effect of leaching temperature and leaching time. The negative effect of high $\mathrm{H}_{2} \mathrm{SO}_{4}$ concentration on $\mathrm{Cr}$ extraction is mainly attributed to the precipitation of metal sulphates that form boundary layers on chromite surfaces, i.e. $\mathrm{Fe}_{2}\left(\mathrm{SO}_{4}\right)_{3}, \mathrm{MgSO}_{4}$ and $\mathrm{Cr}_{2}\left(\mathrm{SO}_{4}\right)_{3}$ [12, 33, 10, 29]. However, at higher leaching temperatures and with long leaching time, there is a possibility that the thin passive boundaries were broken thus improving diffusion and 
mass transfer.

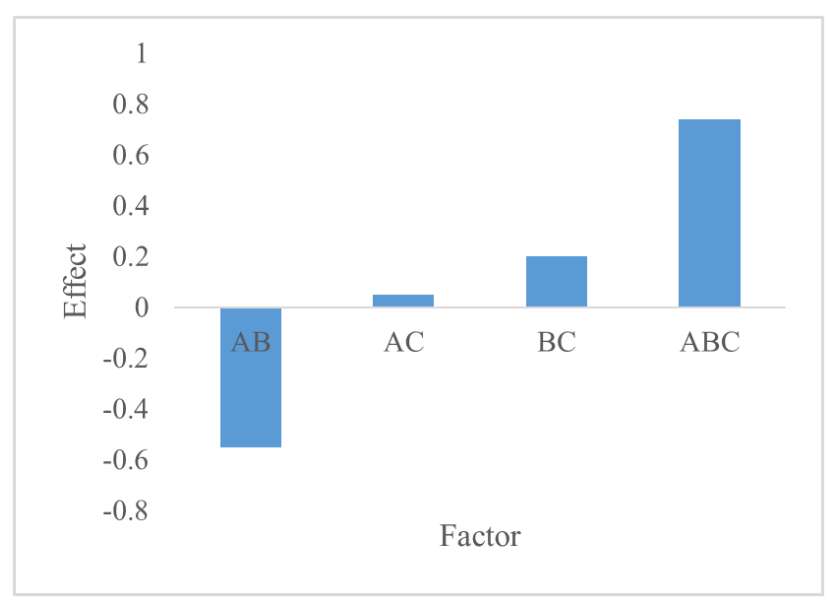

Figure 9. Factor interaction effects from the 24 full factorial design.

\subsection{Optimization of Significant Factors}

The re-fitted second order model was derived as:

$$
\hat{\mathrm{Y}}=6.13-0.13 \times 1-0.098 \times 2
$$

Where,

$\mathrm{x}_{1}=$ oxygen flowrate, $\mathrm{x}_{2}=$ leaching time, within predictor variable limits of:

$$
-\lambda \leq x_{i} \leq+\lambda ; i=1,2
$$

Where,

$\mathrm{X}_{i}$ are coded predictor variables and $\lambda=2^{(\mathrm{k}-\mathrm{q}) 1 / 4}=1.414$ (for $\mathrm{k}=2, \mathrm{q}=0$ ) is the distance of the axial points from the centre of the CCRD that gives the limits of the valid region under experimentation.

For quadratic regression models, the point for which the response is optimized is the point at which the partial derivatives $\partial \mathrm{y} / \partial \mathrm{x} 1 ; \partial \mathrm{y} / \partial \mathrm{x} 2 \ldots \partial \mathrm{y} / \partial \mathrm{xk}$, are all equal to zero. This point is called the stationary point. However, since the re-fitted model in Eq. (2.3) is linear, the maximum response coincides with the distance of the axial points from the center of the CCRD that gives the limits of the valid region under experimentation. The optimum $\mathrm{Cr}$ values were therefore calculated using Eq. (2.3). Using coded values of $\mathrm{x}_{1}=1.414$ for optimum oxygen flowrate and $\mathrm{x}_{2}=1.414$ for optimum leaching time. The predicted $\mathrm{Cr}$ extraction was evaluated as:

$$
\hat{\mathrm{Y}}=5.81 \%
$$

The response surface for the optimized $\mathrm{Cr}$ extraction is presented in Figure 10. Analysis of the response surface seems to indicate that it is possible to achieve a high $\mathrm{Cr}$ extraction at minimal time and minimal oxygen flowrate.

Confirmatory experiments to check the predicted $\mathrm{Cr}$ extraction was performed at $15 \mathrm{~mL} / \mathrm{min}$ for optimum oxygen flowrate and $3 \mathrm{hrs}$ for optimum leaching time and the average Cr extraction obtained was:

$$
\hat{\mathrm{Y}}=7.0 \%
$$

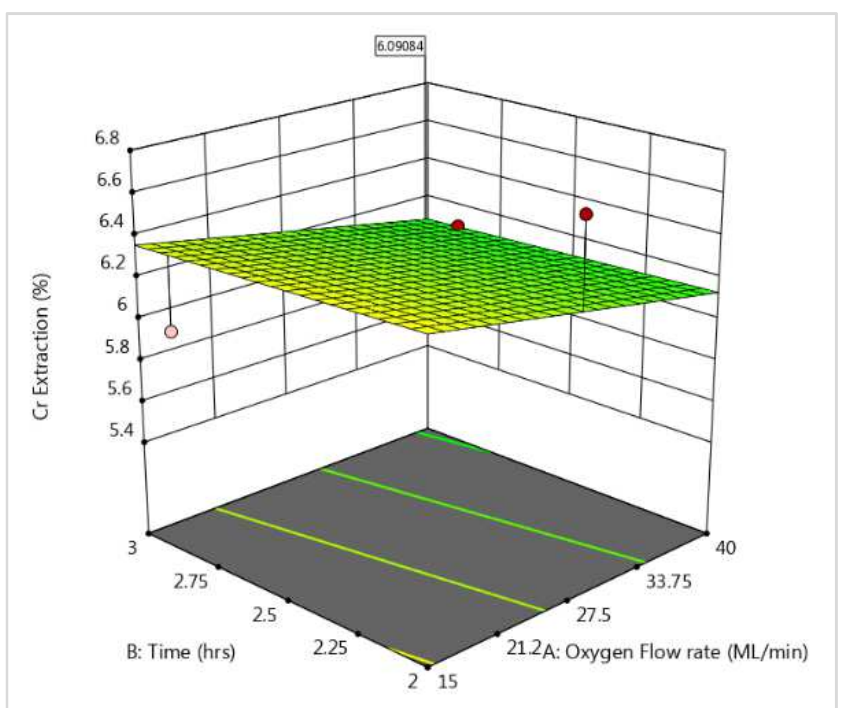

Figure 10. 3D response surface for Cr extraction as a function of time and oxygen flowrate.

Table 5. Cr extraction at optimum leaching conditions.

\begin{tabular}{llll}
\hline Parameter & $\begin{array}{l}\text { Oxygen Flowrate } \\
\text { (mL/min) }\end{array}$ & $\begin{array}{l}\text { Time } \\
\text { (hrs) }\end{array}$ & $\begin{array}{l}\text { Cr Extraction } \\
\text { (\%) }\end{array}$ \\
\hline Model & 15 & 3 & 5.8 \\
Confirmatory tests & 15 & 3 & 7.0 \\
\hline
\end{tabular}

\subsection{Effect of Solid to Liquid Ratio}

This section discusses the influence of solid to liquid ratio (pulp density) on the $\mathrm{Cr}$ extraction process. Optimised leaching conditions derived in the CCRD experimentation were fixed and used, as shown in Table 6 . The motivation to evaluate the effect of the solid to liquid ratio on the process was mainly influenced by the low $\mathrm{Cr}$ extractions obtained at the fixed solid to ratio of $1: 3$ in prior experiments. From an industrial point of view, the 1:3 solid to liquid ratio was initially selected because it aligns with the solid content that is generally required for minimum engineering design and practical operations. Financially, this commonly justifies the capital and operational expenditures (capex and opex) typical of hydrometallurgical applications. For instance, less reagents (\$/unit) will be required to process suitable throughput $(\mathrm{t} / \mathrm{hr})$ with sizeable equipment and ease of handling the liquid stream of the leach process.

The $\mathrm{Cr}$ extraction results obtained from experiments ran at different solid to liquid ratios using optimised leaching conditions are exhibited in Table 6 and Figure 11. A Cr extraction of $7.6 \%$ was obtained at $1: 2$ solid to liquid ratio and $36.8 \%$ at $1: 26$ solid to liquid ratio. The data shows an exponential increase in $\mathrm{Cr}$ extraction at densities lower than 1:10. The high chromium extraction obtained at the low solid to liquid ratios could be attributed to the dispersion effect of mineral particulate at low slurry densities as well as excess availability of reactants. At high slurry densities, the UG-2 material was observed to have an affinity to form temporary electrostatic bonds which reduced the surface area for optimum contact between solids and reactants. As a result, this reduced the leaching efficiencies of chromium from the 
chromite mineral. Noting that $\mathrm{Cr}$ extraction in acid leaching is predominantly from the chrome phase (Table 2), the $36.8 \%$ $\mathrm{Cr}$ extraction, therefore represents a 1.33 wt.\% decrease in chrome content from 3.63 wt.\% to 2.3 wt.\%. Although the target for the solubility limit of chrome to deport in the silica glass phase is approximately $1.8 \mathrm{wt} \%$ and below [7], the actual $\mathrm{Cr}$ content in current smelter operations tends to fluctuate between 3.6 wt. $\%$ and 1.8 wt.\%. Therefore, the $\mathrm{Cr}$ reduction from 3.63 wt. $\%$ to $2.30 \mathrm{wt} . \%$ achieved in the current study is considered acceptable for PGM smelting processes. The reduced chrome content to $2.30 \mathrm{wt} \% \%$ in furnace feed, although slightly above the $1.8 \mathrm{wt} \%$ target, signifies improvement in metallurgical efficacies of PGM smelting furnaces in terms of specific energy consumptions and PGM recoveries due to the reduced slag refractoriness and viscosity. Other benefits include increased refractory lifespan and high furnace utilization due to improved furnace availability.

Table 6. UG-2 concentrates acid leaching conditions.

\begin{tabular}{|c|c|c|c|c|c|c|c|}
\hline & $\mathbf{O 2}$ & Time & $\mathrm{H}_{2} \mathrm{SO}_{4}$ & Temp & Agitation & S: L & Cr Extraction \\
\hline & $\mathrm{mL} / \mathrm{min}$ & Hours & $\%$ & $\left({ }^{\circ} \mathrm{C}\right)$ & (rpm) & $(\%)$ & $(\%)$ \\
\hline 1 & 15 & 3 & 45 & 85 & 1000 & $1: 26$ & 36.8 \\
\hline 2 & 15 & 3 & 45 & 85 & 1000 & $1: 18$ & 25.4 \\
\hline 3 & 15 & 3 & 45 & 85 & 1000 & $1: 10$ & 14.4 \\
\hline 4 & 15 & 3 & 45 & 85 & 1000 & $1: 2$ & 7.6 \\
\hline
\end{tabular}

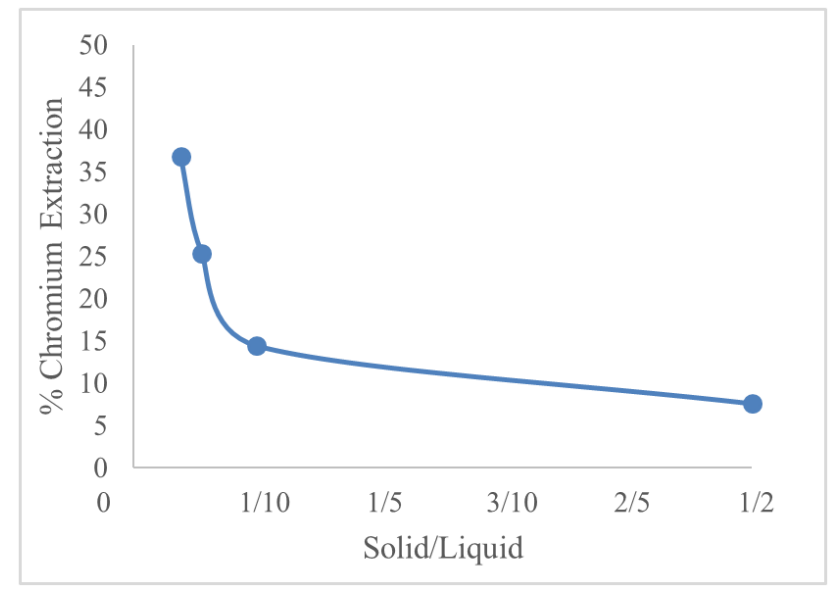

Figure 11. Cr extraction as a function of solid to liquid ratio.

\subsection{Effect of the Acid Leach Process on BMs and PGMs}

The key advantage of the acid leach process clearly involves the leaching of deleterious metals such as chromium and iron contained in oxidic gangue minerals. However, the downside of the process is the partial co-dissolution of base metals and PGMs contained in value minerals. Maximum nickel and copper extractions of 10.0 and $24.5 \%$, respectively, were observed, whilst a fraction of partially dissolved PGMs mainly included rhodium (8.0\%) and platinum $(9.0 \%)$. The dissolved value metals can be recovered through a process that involves conventional pretreatment solution techniques and subsequent hydrometallurgical processes in the base metal refinery (BMR). The proposed process flowsheet for the hydrometallurgical extraction of $\mathrm{Cr}$ is presented in Figure 12.

A sequential precipitation method can be employed to purify the leach solution by recovering deleterious metals prior to the first atmospheric leach stage of the BMR. A treatment process that involves the recovery of iron via a jarosite process can precede the precipitation of chromium as chromium hydroxide by adjusting $\mathrm{pH}$ to $4-5$. This can be followed by charging the solution into the first atmospheric leach stage of the BMR. The purpose of this stage is to generally extract nickel from the Ni-Cu-Fe-S Peirce-Smith convertor matte while precipitating copper and PGMs from the spent electrolyte [17]. The composition of the spent electrolyte is mainly characterised by copper sulphate, sulphuric acid and dissolved rhodium, ruthenium, and iridium as PGMs [17]. The leach solution from this stage is normally treated in the nickel crystallization unit operation to recover nickel as nickel sulphate, while the residue containing precipitated copper and PGMs is treated in the pressure leaching unit operation [17].

Thus, the solution from the proposed chromium leaching process can be incorporated into the first atmospheric leaching stage of the BMR.

\subsection{Economic Implications of the Chrome Reduction}

In general, the economic viability and process efficiency of PGMs smelters are mainly influenced by the chemical quality of the flotation concentrates, i.e., chrome content and other refractory oxidic phases. Therefore, the economic viability of the PGMs smelters is a function of operating costs (opex) which are typically defined in terms of furnace specific energy consumptions (SEC) in $\mathrm{kWh} / \mathrm{t}$, and process efficiency, which is based on the recovery of PGMs. All these aspects are fundamentally linked to the slag chemistry which determines the slag liquidus temperatures and slag viscosities. High liquidus temperatures increase SEC, while high slag viscosities promote poor recovery of PGMs.

The proposed chromium leach process has demonstrated the potential to reduce chrome and other oxidic phases using a less energy intensive approach. The process reduced chrome from 3.6 wt.\% to $2.3 \mathrm{wt} . \%$ in smelter feed under leaching conditions shown in Table 6. Table 7 shows the chemical composition of the major phases that are bound to influence slag chemistry after leaching.

Table 7. Chemical composition of smelter feed concentrates after leaching.

\begin{tabular}{llll}
\hline $\mathrm{Cr}_{2} \mathbf{O}_{3}$ & MgO & Total Fe & $\mathbf{S i O}_{2}$ \\
\hline 2.3 & 21.1 & 9.4 & 44.3 \\
\hline
\end{tabular}


This is a pointer towards a positive influence on SEC and PGMs recovery for the smelters. A reduction on SECs translates into huge savings for the smelters. While this is true, it is also worth noting that the Cr reduction is even more meaningful to junior platinum producers who are penalised by smelters for producing concentrates with high chrome contents that are above contractual obligations. The penalties imposed are typically in orders of millions of Rands for breaching the contractual obligations by a fraction of $\%$ chrome. For the junior platinum producers, it is estimated that the costs associated with the proposed leach process could be offset by the huge savings realised from averting the penalties charged by smelters.

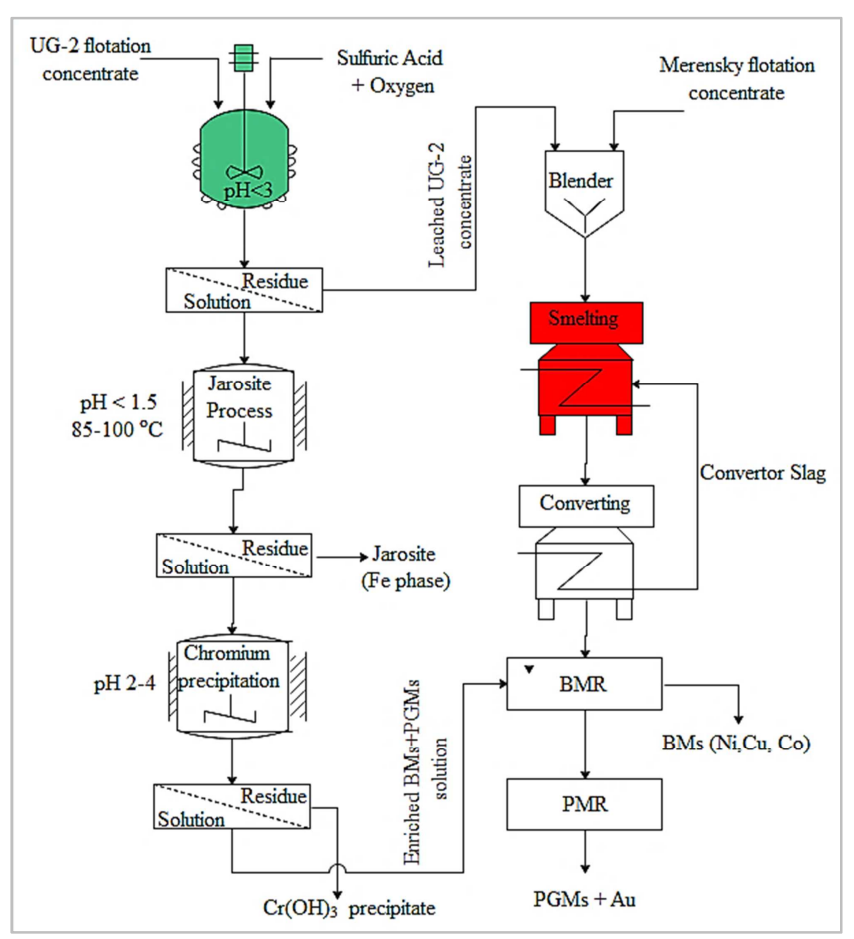

Figure 12. Proposed process flowsheet.

\section{Conclusions}

The overall purpose of employing a hydrometallurgical method of extracting $\mathrm{Cr}$ from the UG-2 concentrate is to develop and propose an alternative process route that reduces chrome content to low levels that are amenable to conventional PGM smelters. Using an acid leach process, the UG-2 concentrate was initially leached with $45 \%$ sulphuric acid at a solid to liquid ratio of $1: 3$, temperature of $80^{\circ} \mathrm{C}$, oxygen flowrate of $15 \mathrm{~mL} / \mathrm{min}$ and $3 \mathrm{hrs}$ reaction time. Under these conditions, the leaching experiment yielded a $\mathrm{Cr}$ extraction efficiency of $7.0 \%$.

Leaching results from the experiment run at different solid to liquid ratios using optimised leaching conditions gave a $\mathrm{Cr}$ extraction of $7.6 \%$ at $1: 2$ solid to liquid ratio and $36.8 \%$ at $1: 26$ solid to liquid ratio. The $36.8 \% \mathrm{Cr}$ extraction represents $1.33 \%$ reduction in $\mathrm{Cr}_{2} \mathrm{O}_{3}$ content from 3.63 wt.\% to 2.3 wt.\% in the UG-2 concentrate. The reduced chrome content to 2.3 wt. $\%$ in furnace feed, although slightly above the $1.8 \mathrm{wt} . \%$ target, signifies the improvement in metallurgical efficacies of PGM smelting furnaces in terms of specific energy consumptions $(\mathrm{kWh} / \mathrm{t})$ and $\mathrm{PGM}$ recoveries due to the reduced slag refractoriness and viscosity. Other benefits will include increased refractory life-span and high furnace utilization due to improved furnace availability.

An increase in acid concentration was found to have a negative effect on $\mathrm{Cr}$ extraction. This was attributed to the precipitation of metal sulphates that form boundary layers on chromite surfaces thereby causing poor diffusion and mass transfer.

The possibility that high $\mathrm{Cr}$ extractions are possible at minimum leaching time and low oxygen flowrates, as observed from the response surface, presents a promising economic feasibility for a less energy intensive UG-2 acid leach process.

Low $\mathrm{Cr}$ extractions were observed at high slurry densities. This was attributed to the UG-2 material's high affinity to form temporary electrostatic bonds which reduce the surface area for optimum contact between solids and reactants. Therefore, the amenability of UG-2 material to leaching could be perceived as a function of its affinity to form temporary electrostatic bonds. Based on this observation, the effect of mechano-activation on the behaviour of the UG-2 concentrate particles could be investigated further with a focus on evaluating the possibility of breaking the electrostatic bonds which in turn might optimise contact between solids and reactants. A recommended reactor for this purpose could be a vertically stirred ball mill; shell dimensions, $\sim 15.0 \mathrm{~cm} \times 30.0 \mathrm{~cm}$ height; ceramic bead size, $\sim 2.5 \mathrm{~mm}$; the ball mill should have an inlet and outlet for slurry circulation. This could be fitted with a 4-blade type of stirrer for efficient suspension of solids and dispersion of injected oxygen as an oxidant.

This study showed that $36.8 \% \mathrm{Cr}$ extraction could be achieved using less energy intensive leaching conditions of up to $80^{\circ} \mathrm{C}$ temperature while operating at a solid to liquid ratio of 1:26. Further investigations could be extended to use of a much lower and more practical solid to liquid ratio while operating at reduced process temperatures.

\section{Nomenclature}

A, B, C, D controlled (main) factors: leaching temperature, leaching time, acid concentration and oxygen flowrate respectively. Interactions of factors: $\mathrm{AB}, \mathrm{AC}, \mathrm{BC}, \mathrm{AD}, \mathrm{BD}$, $\mathrm{CD}, \mathrm{ABC}, \mathrm{ABD}, \mathrm{ACD}, \mathrm{BCD}$, and $\mathrm{ABCD}$.

\section{Acknowledgements}

Eastern Platinum concentrator, Lonmin (Pty) Ltd, South Africa, is gratefully acknowledged for the UG-2 concentrate used in this study. The National Research Foundation, South African Minerals to Metals Research Institute and the Department of Science and Innovation of South Africa are gratefully acknowledged for their financial contribution to the research. Finally, Betachem (Pty) Ltd is gratefully 
acknowledged for their financial contribution and ASEM investigation of the material.

\section{References}

[1] Amer, A. M., (1992). Processing of Ras-Shait chromite deposits. Hydrometallurgy, 28 (1), pp. 29-43.

[2] Barnes, A. R. and Newall, A. F., (2006). Spinel removal from PGM smelting furnaces. Southern African Pyrometallurgy 2006, pp. 77-88.

[3] Biermann, W. J. and Heinrichs, M., 1960. The attack of chromite by sulphuric acid. Canadian Journal of Chemistry, 38 (9), pp. 1449-1454.

[4] Box, G. E. P., Hunter, W. G., Hunter, J. S., (1978). Statistics for Experimenters: An Introduction to Design, Data Analysis and Model Building. John Wiley and Sons, New York.

[5] Bronsted, J. N., (1931). On The Dissolution of Metals in Acids. Journal of American Chemitry Society. Vol. 53, Issue 10, pp. 3624-3644. https://doi.org/10.1021/ja01361a006.

[6] Daniel, C., 1959. Use of Half Normal plots in Interpreting Factorial Two Level Experiments. Technometrics, 1 (4), 311341.

[7] Du Preez, R. C., (2010). Effect of lime additions and bulk chromium content on chromium deportment in smelter matteslag systems (Doctoral dissertation, Stellenbosch: Stellenbosch University).

[8] Eksteen, J. J., Van Beek, B. and Bezuidenhout, G. A., (2011). Cracking a hard nut: an overview of Lonmin's operations directed at smelting of UG2-rich concentrate blends. Journal of the Southern African Institute of Mining and Metallurgy, 111 (10), pp. 681-690.

[9] Free, M. L., (2013). Hydrometallurgy: fundamentals and applications. John Wiley \& Sons.

[10] Geveci, A., Topkaya, Y. and Ayhan, E., (2002). Sulfuric acid leaching of Turkish chromite concentrate. Minerals Engineering, 15 (11), pp. 885-888.

[11] Hay, M. P. and Roy, R., (2010). A case study of optimising UG2 flotation performance. Part 1: Bench, pilot and plant scale factors which influence $\mathrm{Cr}_{2} \mathrm{O}_{3}$ entrainment in UG2 flotation. Minerals Engineering, 23 (11), pp. 855-867.

[12] Jiang, M., Zhao, Q., Liu, C., Shi, P., Zhang, B., Yang, D., Saxén, H. and Zevenhoven, R., (2014). Sulfuric acid leaching of South African chromite. Part 2: optimization of leaching conditions. International Journal of Mineral Processing, 130, pp. 102-107.

[13] Jones, R. T. and Geldenhuys, I. J., (2011). The pros and cons of reductive matte smelting for PGMs. Minerals Engineering, 24 (6), pp. 495-498.

[14] Jones, R. T., Geldenhuys, I. J. and Reynolds, Q. G., (2009). Recovery of base metals and PGMs in a DC alloy-smelting furnace. Journal of the Southern African Institute of Mining and Metallurgy, 109 (10), pp. 595-600.

[15] Jones, R. T., (2005). An overview of Southern African PGM smelting. Nickel and Cobalt 2005: Challenges in Extraction and Production, pp. 147-178.
[16] Jones, R. T. and Kotze, I. J., (2004). DC arc smelting of difficult PGM-containing feed materials. First International Platinum Conference, 'Platinum Adding Value', Sun City, South Africa, 3-7 October 2004. South African Institute of Mining and Metallurgy, Johannesburg. pp. 33-36.

[17] Lamya, R. M. (2007) A fundamental evaluation of the atmospheric pre-leach section of the nickel-copper matte treatment process-213, University of Stellenbosch.

[18] Maharaj, L., Loveday, B. K. and Pocock, J., (2011). The benefit of separate milling of silicate and chromite particles for chromite-rich UG-2 ores. South African Journal of Chemical Engineering, 16 (1), pp. 1-16.

[19] Maroo, S., Chandramohan, P., Srinivasan, M. P. and Velmurugan, S., 2020. Chemical dissolution of iron substituted chromium oxide by dissolved ozone. Progress in Nuclear Energy, 120, p. 103189.

[20] Nell, J., (2004). Melting of platinum group metal concentrates in South Africa. Journal of the Southern African Institute of Mining and Metallurgy, 104 (7), pp. 423-428.

[21] Napier-Munn, T. and Wills, B. A., (2006). Wills' mineral processing technology: An introduction to the practical aspects of ore treatment and mineral recovery. Elsevier.

[22] Rivera Li Kao, O. and Garbers-Craig, A., 2020. Impact of Phase Evolution in Platreef and UG-2 Concentrates on Matte Drainage in the Black Top of a Platinum Group Metal Smelter. Mineral Processing and Extractive Metallurgy Review, pp. 113.

[23] Shaw, A., De Villiers, L. P. V. S., Hundermark, R. J., Ndlovu, J., Nelson, L. R., Pieterse, B., Sullivan, R., Voermann, N., Walker, C., Stober, F. and McKenzie, A. D., (2013). Challenges and solutions in PGM furnace operation: high matte temperature and copper cooler corrosion. Journal of the Southern African Institute of Mining and Metallurgy, 113 (3), pp. 00-00.

[24] Tague, N. R., 2004. The Quality Toolbox, Second Edition, ASQ Quality Press, Wisconsin.

[25] Takeno, N., (2005). Atlas of Eh-pH diagrams. Geological survey of Japan open file report, 419, p. 102.

[26] Tripathy, S. K. and Murthy, Y. R., (2012). Modeling and optimization of spiral concentrator for separation of ultrafine chromite. Powder Technology, 221, pp. 387-394.

[27] Valenta, M. M. and Mapheto, H., (2011). Application of fundamentals in optimizing platinum concentrator performance. Journal of the Southern African Institute of Mining and Metallurgy, 111 (2), pp. 93-99.

[28] Wilkinson, L., 2006. Revising the Pareto chart. American Statistician, Vol. 60, No. 4, pp. 332-334.

[29] Vardar, E., Eric, R. H. and Letowski, F. K., (1994). Acid leaching of chromite. Minerals Engineering, 7 (5-6), pp. 605-617.

[30] Zhang, B., Shi, P. and Jiang, M., (2016). Advances towards a clean hydrometallurgical process for chromite. Minerals, 6 (1), p.

[31] Zhang, X., Li, G., Wu, J., Xiong, N. and Quan, X., 2020. Leaching of valuable elements from the waste chromite ore processing residue: a kinetic analysis. ACS omega, 5 (31), pp. 19633-19638. 
[32] Zhao, Q., Liu, C., Shi, P., Sun, L., Jiang, M., Saxen, H. and Zevenhoven, R., 2020. Cleaner production of chromium oxide from low Fe (II)-chromite. Minerals, 10 (5), p. 460.
[33] Zhao, Q., Liu, C., Shi, P., Zhang, B., Jiang, M., Zhang, Q., Saxén, H. and Zevenhoven, R., (2014). Sulfuric acid leaching of South African chromite. Part 1: Study on leaching behavior. International Journal of Mineral Processing, 130, pp. 95-101. 